\title{
The role of tissue-specific microbiota in initial establishment success of Pacific oysters
}

\author{
Ana Lokmer, ${ }^{1 *}$ Sven Kuenzel, ${ }^{2}$ John F. Baines ${ }^{2,3}$ and \\ Karl Mathias Wegner ${ }^{1}$ \\ ${ }^{1}$ Helmholtz Centre for Polar and Marine Research, \\ Alfred Wegener Institute, Coastal Ecology, Wadden Sea \\ Station Sylt, List, Sylt, Germany. \\ ${ }^{2}$ Max Planck Institute for Evolutionary Biology, \\ August-Thienemann-Strasse 2, D-24306 Plön, \\ Germany. \\ ${ }^{3}$ Institute for Experimental Medicine, \\ Christian-Albrechts-University of Kiel, \\ Arnold-Heller-Strasse 3, D-24105 Kiel, Germany.
}

\section{Summary}

Microbiota can have positive and negative effects on hosts depending on the environmental conditions. Therefore, it is important to decipher hostmicrobiota-environment interactions, especially under natural conditions exerting (a)biotic stress. Here, we assess the relative importance of microbiota in different tissues of Pacific oyster for its successful establishment in a new environment. We transplanted oysters from the Southern to the Northern Wadden Sea and controlled for the effects of resident microbiota by administering antibiotics to half of the oysters. We then followed survival and composition of haemolymph, mantle, gill and gut microbiota in local and translocated oysters over 5 days. High mortality was recorded only in non-antibiotic-treated translocated oysters, where high titres of active Vibrio sp. in solid tissues indicated systemic infections. Network analyses revealed the highest connectivity and a link to seawater communities in the haemolymph microbiota. Since antibiotics decreased modularity and increased connectivity of the haemolymph-based networks, we propose that community destabilization in non-treated translocated oysters could be attributed

\footnotetext{
Received 25 May, 2015; accepted 27 November, 2015. *For correspondence. E-mail alokmer@awi.de; Tel. +49 46519564 203; Fax +4946519564 200. Originality significance statement: This is the first study to examine the role of microbiota for the establishment success hosts in a new environment. The host examined is the Pacific oyster, an important invasive and aquaculture species. It also represents the first comprehensive account of Pacific oyster microbiota in the different tissues in order to assess their significance for the oyster fitness and interactions with the environment.
}

to interactions between resident and external microbiota, which in turn facilitated passage of vibrios into solid tissues and invoked disease. These interactions of haemolymph microbiota with the external and internal environment may thus represent an important component of oyster fitness.

\section{Introduction}

Exposure to novel environmental conditions can impose biotic and abiotic stress on organisms (Shea and Chesson, 2002; Hedge and Johnston, 2014). However, such stressors will not only affect the organism directly, but also the microbiota associated with it. Disturbances of fine-tuned interactions among the host, microbiota and the environment may have lethal consequences for the host (Sison-Mangus et al., 2015). Among other functions, resident microbiota are involved in the host immune defence by preventing colonization and establishment of pathogens (Kamada et al., 2013a; Abt and Pamer, 2014; Desriac et al., 2014). While adjustments in community composition can maintain such beneficial functions even under changing environmental conditions, excessive levels of stress can destabilize communities and facilitate shift towards pathogenic states (Rosenberg et al., 2007; Pita et al., 2013; Bauvais et al., 2015; Lokmer and Wegner, 2015). As stability is important for community functioning (Shade et al., 2012), environmental disturbances may bear multilayered consequences beyond the direct effects on the host.

One extreme form of environmental shifts is translocation of organisms to new habitats, within or beyond their normal range. This can happen either unintentionally (e.g. species invasions) or intentionally, like in aquaculture where it is a common practice (Galil et al., 2014). Such habitat shifts will likely be associated with drastic changes in environmental conditions and will not only lead to new interactions of the new environment with the host, but also with its associated microbiota. Further, both the host and its microbiota will not only be affected by changes in abiotic conditions, but will also be exposed to novel biotic environments, including microbes (Jones and Gomulkiewicz, 2012). In humans, for example, travelling to exotic destinations is accompanied by shifts in microbiota composition, potentially leading to health problems (David et al., 2014). While these new colonizers may not harm the 


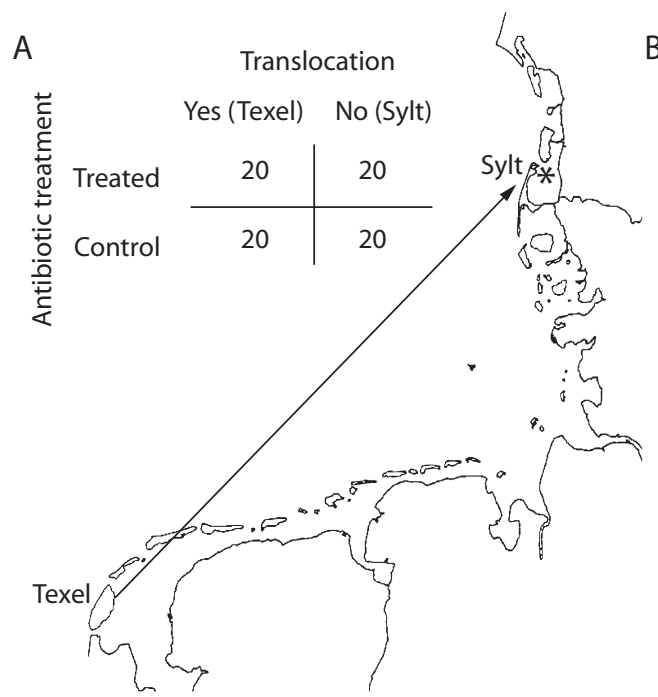

B

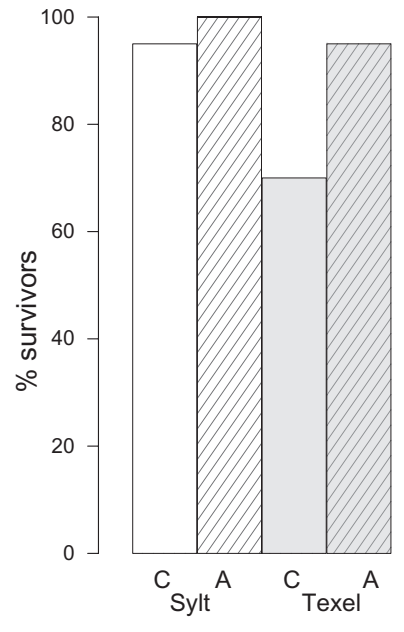

Fig. 1. (A) Experimental design showing the number of oysters within each group. The experimental site is marked by asterisk (*). Experiment duration: 5 days. (B) End-point survival 5 days after translocation and antibiotic treatment $(n=80)$. A, antibiotic-treated; $\mathrm{C}$, control. organism directly, their interactions with resident microbiota might lead to unforeseeable consequences that cannot be explained by examining the host in isolation (Brown et al., 2009; Koskella et al., 2011; Rillig et al., 2015). To conclusively determine the role of microbiota in colonization success, one needs to investigate the threeway interactions between the host, its microbiota and the environment.

One species that combines several aspects of novel habitat colonization is the Pacific oyster (Crassostrea gigas). This species successfully invaded and significantly altered coastal habitats worldwide (Kochmann et al., 2008; Wagner et al., 2012). Moreover, it is a common aquaculture practice to transfer oysters of all life stages between distant cultivation sites (Muehlbauer et al., 2014).

Both transfer and invasion introduce potential mismatches between hosts, their resident, co-adapted microbiota and the novel external biotic environment, including microbes. In other words, the resident microbiota find themselves in a new microbial context, encountering related but locally adapted ecotypes (Martiny et al., 2006; Cohan and Koeppel, 2008) that may alter the microbial community dynamics within the host (Brown et al., 2009; Koskella et al., 2011; Rillig et al., 2015). Despite the applied and fundamental relevance, the consequences of a new microbial context are largely unknown both for the host-associated microbiota as a whole as well as for functionally relevant groups involved.

One important lineage of symbionts and pathogens of marine animals are the bacteria of the genus Vibrio (for example, see Hoffmann et al., 2010; Rowley et al., 2014). In oysters, several strains have been implicated in environment-dependent diseases (Garnier et al., 2007; Elston et al., 2008), invoking rapid evolutionary responses in host populations (Wendling and Wegner, 2015). In addition, the prevalence of pathogenic Vibrio spp. in oysters depends on geographic origin (Petton et al., 2015). Vibrio spp. and their close relatives of the family Vibrionaceae thus represent an ideal focus group to investigate the effects of a new microbial context on the dynamics of opportunistic pathogens.

It is also likely that the disturbance effects will vary among the different tissues of a host. In mammals, for example, gut microbiota are important for immunity and certain changes are related to potentially life-threatening conditions (Kamada et al., 2013b; Ferreira et al., 2014), while the belly-button communities are much less likely to have such an effect (Hulcr et al., 2012). In oysters, haemolymph communities seem to mirror the host condition, as they tend to have low diversity and are dominated by few strains in moribund animals (Garnier et al., 2007; Lokmer and Wegner, 2015). How the microbiota in other tissues relate to oyster condition and to each other is far less known, because most studies have focused on whole body homogenates (Beleneva et al., 2007) or single tissues (Zurel et al., 2011; Trabal et al., 2012; Wegner et al., 2013; Trabal Fernandez et al., 2014). The variation in microbiota composition between the tissues was rarely considered in bivalves (but see Antunes et al., 2010; King et al., 2012), especially in the context of host fitness (but see Meisterhans et al., 2015).

In this study, we set out to experimentally explore how microbiota in different tissues of Pacific oysters are affected by translocation and how the new microbial context affects oyster fitness in a new environment. To do so, we transplanted Pacific oysters from the Southern Wadden Sea (Texel, Netherlands) to the Northern Wadden Sea (Sylt, Germany), and monitored short-term shifts in microbiota composition in different oyster tissues 
during the initial phase of establishment in the new habitat (Fig. 1A). The oyster populations on Texel and Sylt have distinct invasion histories and are clearly differentiated by mitochondrial haplotype frequencies (Moehler et al., 2011). In order to distinguish between the oyster- and microbiota-related effects on the establishment success, we treated half of the oysters with antibiotics, thus minimizing the interactions between resident microbes and new colonizers, while the other half was transplanted with their natural resident microbiota. We followed oyster survival and changes in diversity, composition and abundance of oyster-associated bacterial communities as a whole, and Vibrionaceae in particular, over the first 5 days in the new habitat. In this way, we could estimate how the composition and diversity of microbiota in different tissues contribute to the successful establishment of Pacific oysters in a new environment.

\section{Results}

\section{Oyster survival and immune parameters}

We observed significant differences in survival between the four oyster groups, with only non-antibiotic treated (control) oysters from Texel showing significantly elevated mortality rates (overall test: $\chi^{2}=12.222$, df $=3, P=0.007$, $n=80$, Fig. 1B, see Table $\mathrm{S} 1$ for pairwise comparisons). The mortality could not be linked to genetic differences between the populations (as it differed between the treated and control oysters from Texel, Table S1) nor to differences in the immune system activity, as neither the total haemocyte count (THC) [analysis of variance (ANOVA): $\left.\mathrm{F}_{3,72}=1.302, \quad P=0.281, \quad n=76\right]$ nor the phagocytosis rate per haemocyte (ANOVA: $F_{3,67}=0.565$, $P=0.640, n=71$ ) differed between the four oyster groups. Plasma protein concentration was affected only by antibiotic treatment and thus could not be linked to the mortality either (ANOVA: antibiotic treatment: $F_{1,71}=11.314, \quad P=0.001$, effect size $=0.136$; origin; $F_{1,71}=0.676, P=0.413$; origin $\times$ treatment: $F_{1,71}=0.528$, $P=0.469, n=75)$.

\section{Distinction between oyster and seawater microbiota}

Bacterial communities in the seawater differed substantially from those found in oyster tissues. The seawater $(n=3)$ and oyster $(n=332)$ communities were similar in terms of evenness [median: seawater $(\mathrm{sw})=0.549$, all oyster samples $=0.641$; Wilcoxon rank sum (RS) test: $P=0.334$, Fig. 2A], but overall species richness was much higher in the seawater (median: $s w=873$, all oyster samples $=310$; Wilcoxon RS test: $P=0.008$, effect size $=-0.142$, Fig. 2B). In contrast, the relative operational taxonomic unit (OTU, 97\% identity) richness of Vibrionaceae was much higher in oyster tissues (median: $\mathrm{sw}=0.006$, oyster $=0.079$; Wilcoxon RS test: $P=0.003$, effect size $=0.159$ ), mainly owing to high Vibrionaceae diversity in the haemolymph (Fig. 2C). The activity of Vibrionaceae - estimated from the colony forming unit (CFU) counts on thiosulfate-citrate-bile salts-sucrose (TCBS) agar - confirmed this pattern, with much higher numbers in the haemolymph than in the seawater (median: haemolymph $=4062.5, \mathrm{sw}=500$; Wilcoxon $\mathrm{RS}$ test: $P=0.004$, effect size $=0.166$, Fig. 2D). All seawater samples were dominated by a handful of taxa belonging to $\alpha$-Proteobacteria and Flavobacteriaceae (Fig. $3 \mathrm{~A}$ and B). The most abundant OTUs in the seawater communities (mean relative abundance $\geq 0.01, n=14$ ) were also found in $85 \%$ of the oyster samples albeit in lower abundance, establishing the seawater as a source of bacteria for the oyster microbiome, especially for the haemolymph [mean, median and range of their combined abundance within oyster samples: haemolymph $=0.059,0.009(0,0.433)$, $n=141$, solid tissues $=0.005,0.002(0,0.083), n=191]$. Nevertheless, the seawater and oyster communities were clearly differentiated by community composition (Fig $3 \mathrm{~A}$ and $B$ ). In addition, non-metric multidimensional scaling (NMDS) plot (Fig. 3A) revealed significantly lower withingroup $\beta$-diversity of seawater compared to oyster microbiota, which was confirmed by Levene's test for homogeneity of multivariate variances (average distance to median: oyster $=0.614$, seawater $=0.201, \quad F_{1,333}=$ 167.9, $P<10^{-6}$, effect size $=0.25$ ).

\section{Factors explaining bacterial community differences within oysters: tissue and oyster individual}

Within oysters, $\alpha$-diversity significantly differed between the studied tissues, with substantially lower diversity observed in the gut and the highest species richness in the haemolymph (Fig. 2A and B; robust Wilcox bootstrapped ANOVA: evenness: $F_{3,81.56}=9.088, P<0.001$, effect size $=$ 0.368; species richness: $F_{3,98.493}=68.052, P \leq 0.001$, effect size $=0.747, n=332$ ). A similar pattern was observed for the relative species richness of Vibrionaceae (Fig. 2C; robust Wilcox bootstrapped ANOVA: $\mathrm{F}_{3,127.508}=$ 7.767, $P<0.001$, effect size $=0.376)$. Positive correlation between the number of cultivable Vibrionaceae and their species richness in the solid tissues [Spearman's $\rho: 0.280$, $P<0.001$, confidence interval $(\mathrm{Cl})=(0.143,0.427)$, Fig. S1D] and the lack of such correlation in the haemolymph (Spearman's $\rho: 0.126, P=0.137$, Fig. S1C) suggest that high Vibrionaceae species richness in solid tissues, but not in haemolymph, may indicate a systemic infection. Unlike species richness, the evenness of Vibrionaceae was negatively correlated with cultivability in all tissues [Fig. S1A and B; haemolymph: Spearman's $\rho$ : $-0.196, P=0.020, \mathrm{Cl}=(-0.239,-0.021)$; solid tissues: Spearman's $\rho:-0.208, P=0.004, \mathrm{Cl}=(-0.347,-0.080)]$, 


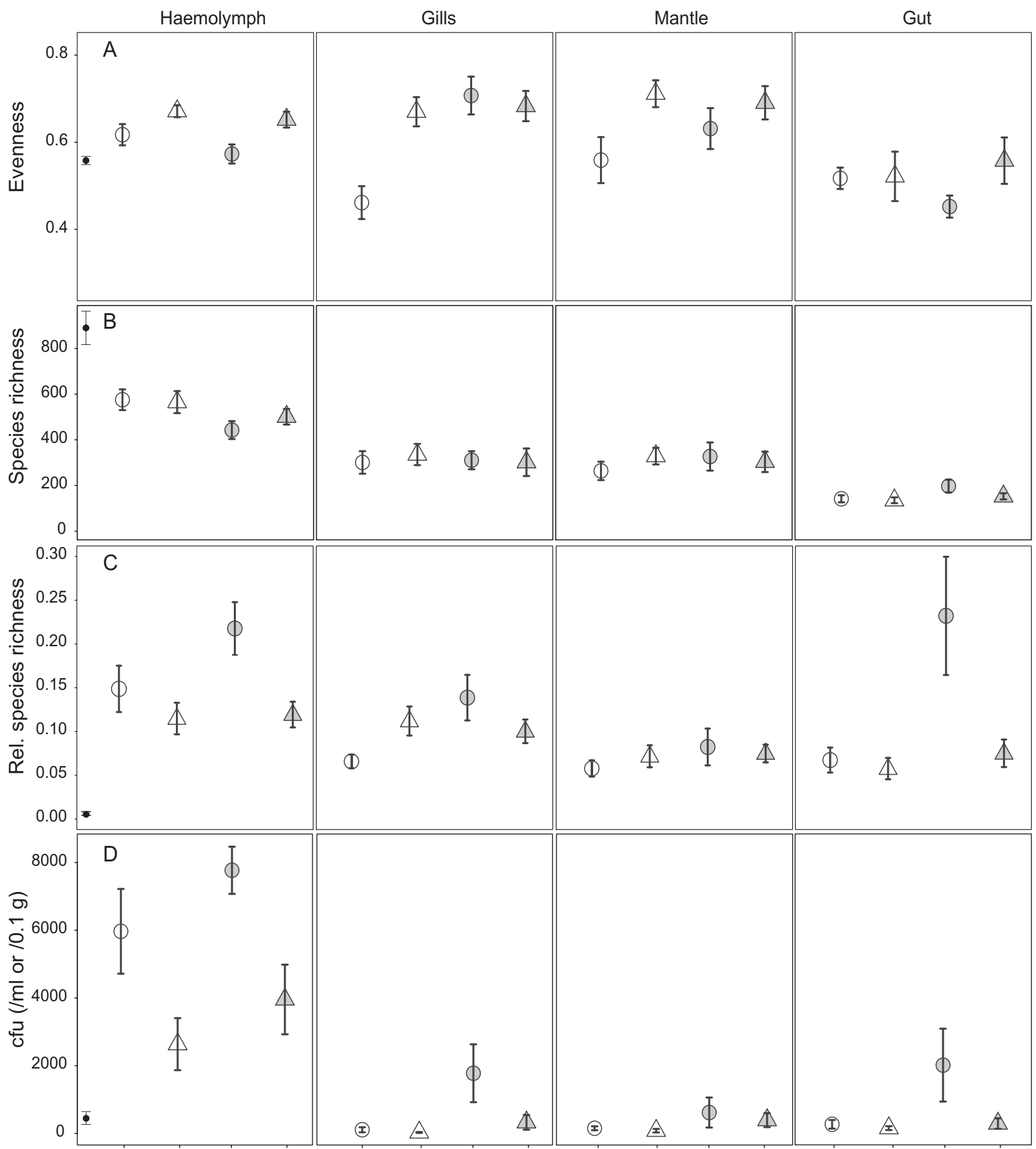

Fig. 2. $\alpha$-Diversity and Vibrionaceae activity in oyster tissues grouped according to oyster origin (clear $=$ Sylt, grey = Texel) and antibiotic treatment $(O=$ control, $\Delta=$ treated): (A) overall evenness and (B) overall species richness; (C) proportion of total species assigned to Vibrionaceae and (D) cultivable Vibrionaceae in $1 \mathrm{ml}$ of haemolymph or approximately $100 \mathrm{mg}$ of solid tissue. Seawater samples (black) are shown in the leftmost plot for reference. Error bars represent standard error of mean.

suggesting that higher overall activity of Vibrionaceae tends to be associated with proliferation of few, potentially pathogenic strains.

Tissue also explained a significant portion of variance in community composition, especially when phylogenetic relatedness was taken into account (compare Bray-Curtis and UniFrac in Fig. 4A), indicating substantial ecological differences between the tissues. Haemolymph communities were clearly distinguished from those in solid tissues by higher relative abundance of $\varepsilon$-Proteobacteria 


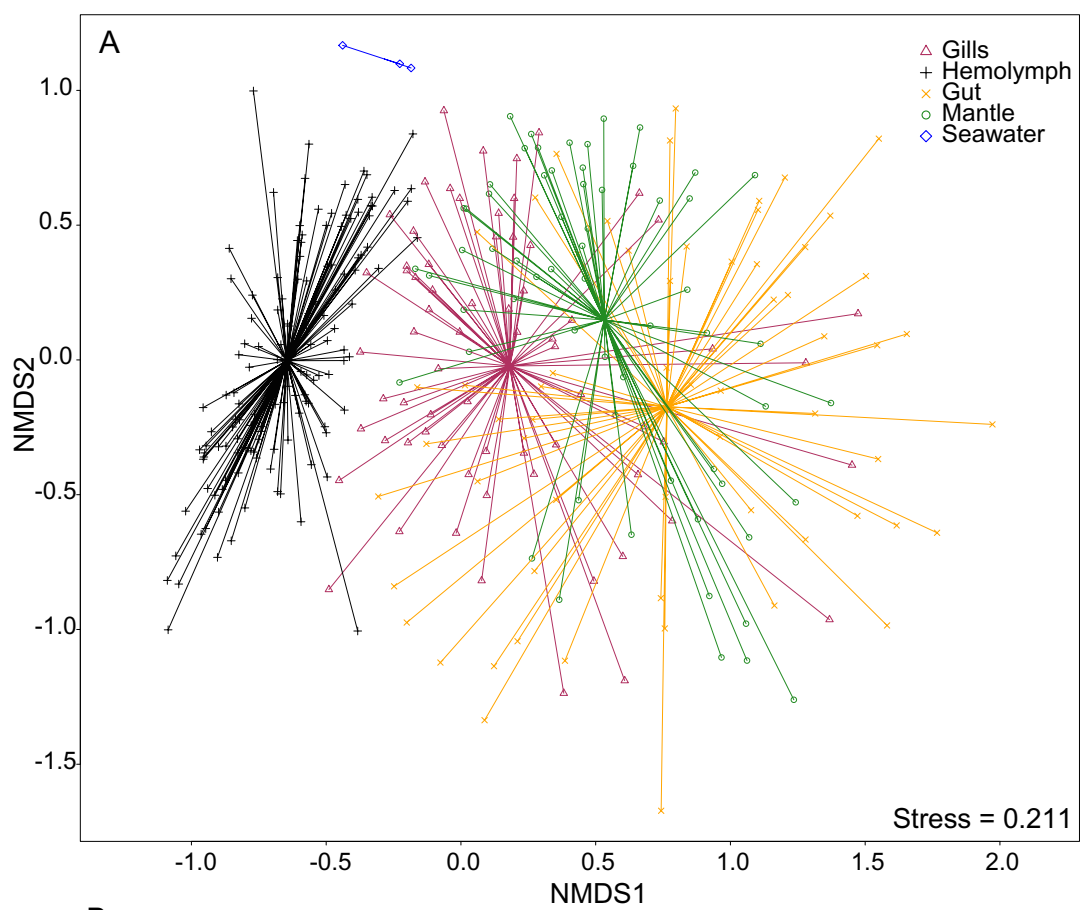

B

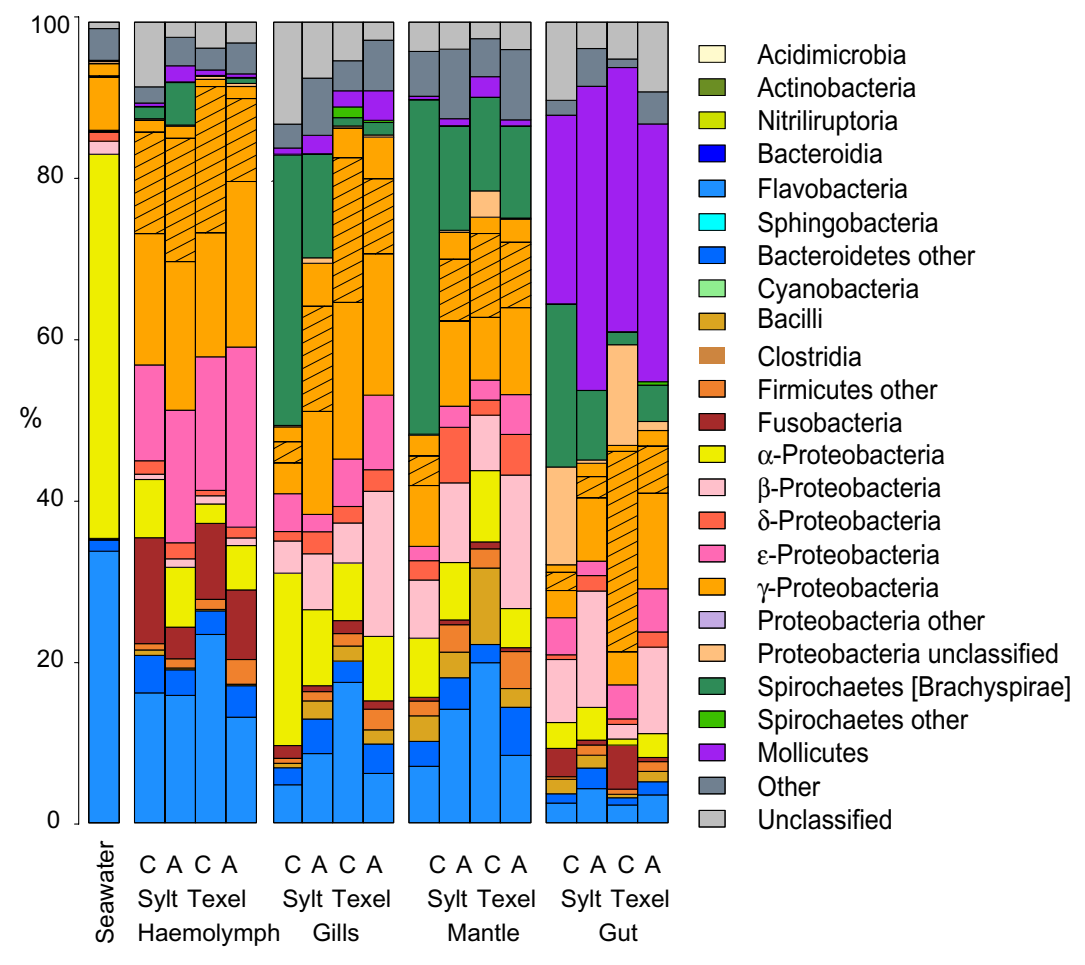

Fig. 3. $\beta$-Diversity and taxonomical composition of seawater and oyster microbiota.

A. NMDS plot of Bray-Curtis distances showing differences between the oyster tissues and the seawater.

B. Mean relative abundance of classes in the seawater and in the tissues, grouped according to oyster origin and treatment. Cross-hatching shows mean relative abundance of Vibrionaceae. A, antibiotic-treated; C, control.
(Arcobacter), Flavobacteria, Fusobacteria (Psychrilyobacter) and $\gamma$-Proteobacteria (Oceanospirillaceae, Vibrionaceae), and fewer Spirochaetes (Brachyspirae) and $\beta$-Proteobacteria (Table S2). Among the solid tissues, the most conspicuous difference was the high abundance of Mollicutes (Mycoplasma) in the gut, while the mantle and gill microbiota differed only slightly.
In addition to the large effect of tissue, a considerable amount of variability in community composition was explained by differences between individual oysters (Fig. 4A). In this case, however, the explained variability was higher when phylogenetic relatedness was disregarded (compare Bray-Curtis and UniFrac in Fig. 4A). 


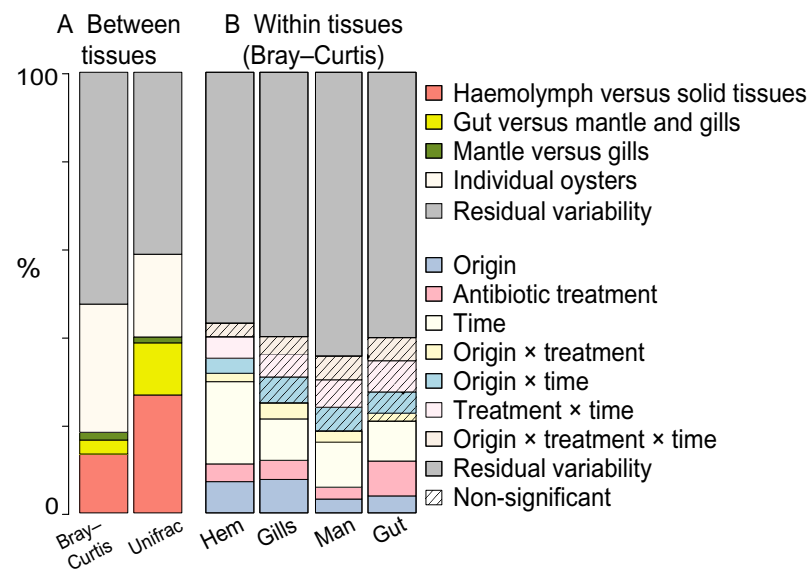

Fig. 4. Variance in community composition explained by $(A)$ tissue type and individual, and (B) oyster origin, antibiotic treatment, time and their interactions in individual tissues. Barplots are graphical representations of Permanova results (cross-hatching shows non-significant factors). Since new oysters were sampled every day, time is partially confounded with between-individual variation.

\section{Factors explaining bacterial community differences between oysters: experimental translocation and antibiotic treatment}

We examined the effects of population origin and antibiotic treatment on overall $\alpha$-diversity and the diversity and activity of Vibrionaceae separately for the haemolymph and solid tissues (Fig. 2). The antibiotic treatment increased species richness and evenness of haemolymph microbiota in both oyster populations (Fig. 2A and B, Table 1, haemolymph model, main effect of treatment) and reduced the diversity (Fig. 2C, Table 2, haemolymph model, main effect of treatment) and cultivability of Vibrionaceae (Fig. 2D, ANOVA: treatment: $\mathrm{F}_{1,135}=13.344, P<0$. 001, origin: $\mathrm{F}_{1,135}=2.509, P=0.116$, treatment $\times$ origin: $\mathrm{F}_{1,135}=$ $0.110, P=0.740, n=141$ ). Interestingly, low evenness of haemolymph microbiota before the transfer to the field correlated with oyster survival (Table 1, haemolymph model, main effect of survival), indicating that disrupted community structure associated with few dominating OTUs may have played a role in the mortalities. In solid tissues, the response to antibiotics depended on the oyster origin. In detail, antibiotics increased the evenness of mantle and gill, but not of gut microbiota in Sylt oysters, while the opposite was true for Texel animals (Fig. 2A, Table 1, solid tissues model, tissue $\times$ treatment $\times$ origin interaction). Although neither the treatment nor translocation affected overall species richness (Fig. 2B, Table 1), the antibiotics significantly reduced diversity of Vibrionaceae in Texel oysters (Fig. 2C, Table 2, solid tissues model, origin $x$ treatment interaction), especially in the gut (Table 2, solid tissues model, tissue $\times$ treatment interaction). The antibiotics also decreased the number of cultivable Vibrionaceae in Texel oysters, while having little effect on Sylt animals (Fig. 2D, ANOVA: treatment: $F_{1,181}=8.227, P=0.005$, origin: $\quad F_{1,181}=12.614, \quad P=0.001$, origin $\times$ treatment: $\left.\mathrm{F}_{1,181}=7.641, P=0.006\right)$.

In order to examine the effects of population origin and antibiotics on $\beta$-diversity, we analysed each tissue separately (Figs 3 and 4). Despite the high temporal/individual variability, the effects of antibiotics and the population signature remained significant throughout the experiment. Although we observed differences in abundance of some minor genera in the haemolymph (mainly assigned to Flavobacteria, $\alpha$ - and $\gamma$-Proteobacteria), Vibrionaceae did not show any significant variation (Table S3). Overall, dominant genera were shared among the oyster groups, but the relative abundance of OTUs belonging to those genera differed. For example, while all haemolymph communities - regardless of treatment or origin - contained bacteria of the genus Arcobacter, Texel and Sylt oysters were characterized by a different set of Arcobacter OTUs (Table S4).

\section{Association networks}

The vast majority $(89.7 \%)$ of associations in the wholeoyster network occurred within tissues (coloured lines in Fig. 5) and only $10.3 \%$ occurred between them (grey lines in Fig. 5). Only haemolymph, however, showed higher connectivity than expected by chance (compared with the connectivity of 1000 random node subsets of the same size, $P<0.05)$. We therefore focused on haemolymph for further analysis, and constructed a network for each treatment $\times$ origin combination to examine microbial association networks in response to antibiotics and translocation (Fig. 6). All resulting networks shared a densely connected area, whose core consisted of the OTUs that were also abundant in the seawater samples ( $\alpha$-Proteobacteria and Flavobacteria), further establishing the intimate connection between haemolymph and the environment. Other motifs, characterized by Arcobacter, Vibrionaceae or/and other $\gamma$-Proteobacteria and some anaerobes, belonging to Fusobacteria and Clostridia, were recovered in each oyster group as well, and they tended to be negatively associated with the first environmental ('seawater') subcluster (Fig. S2). These shared OTUs had higher than average degree and represented $23 \pm 5 \%$ of nodes within the individual networks (Fig. 6, Table S5). Despite these shared features and although the antibiotic treatment affected only the composition of minor genera within the haemolymph microbiome (Table S3), it significantly altered the association network structure, as antibiotics strongly reduced modularity and increased the connectivity of the networks (Table 3, Table S5). In contrast to control oysters from Sylt, the network based on the control oysters from Texel consisted of more sparsely 
Microbiota and oyster establishment 7

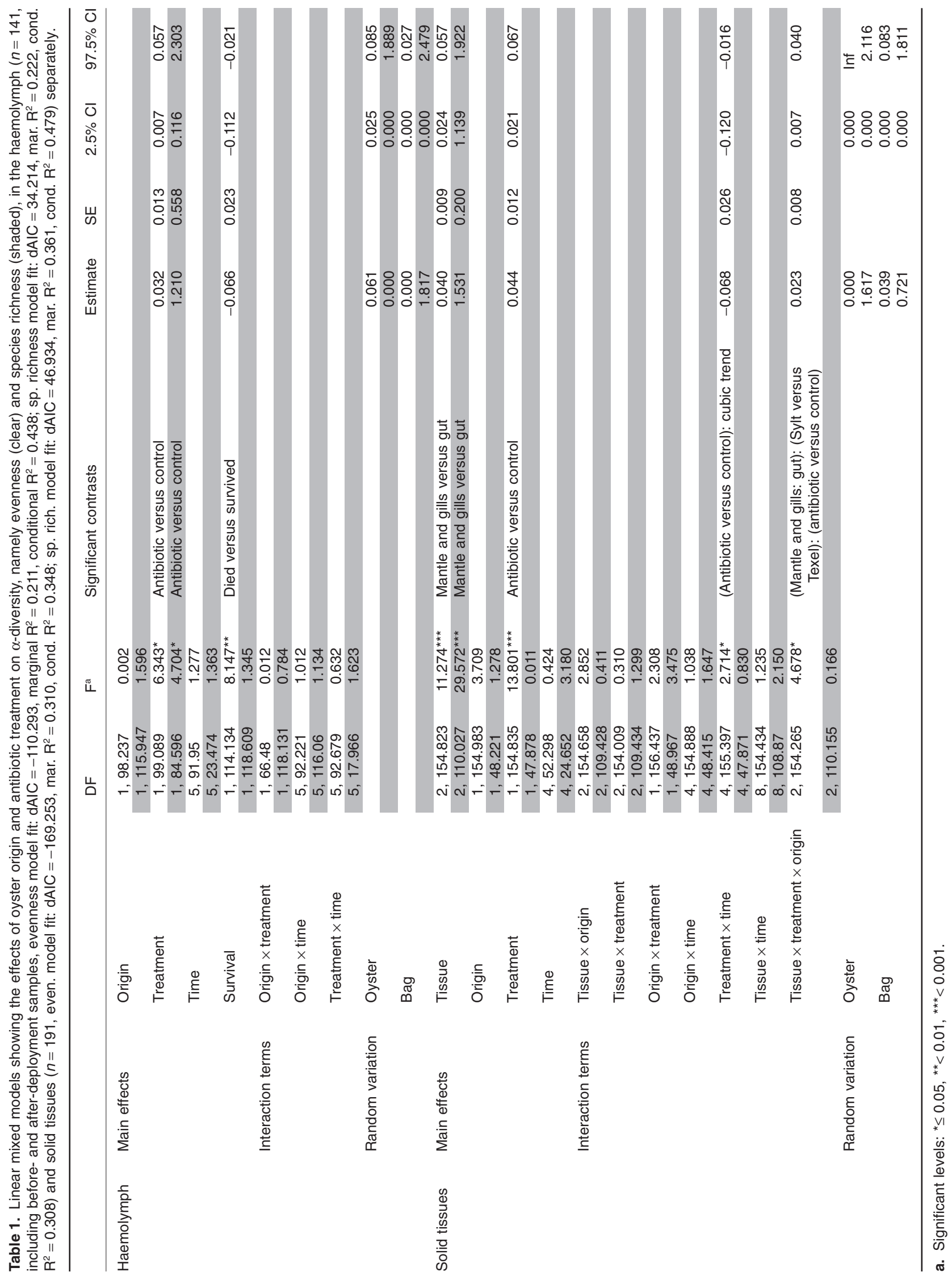


8 A. Lokmer, S. Kuenzel, J. F. Baines and K. M. Wegner

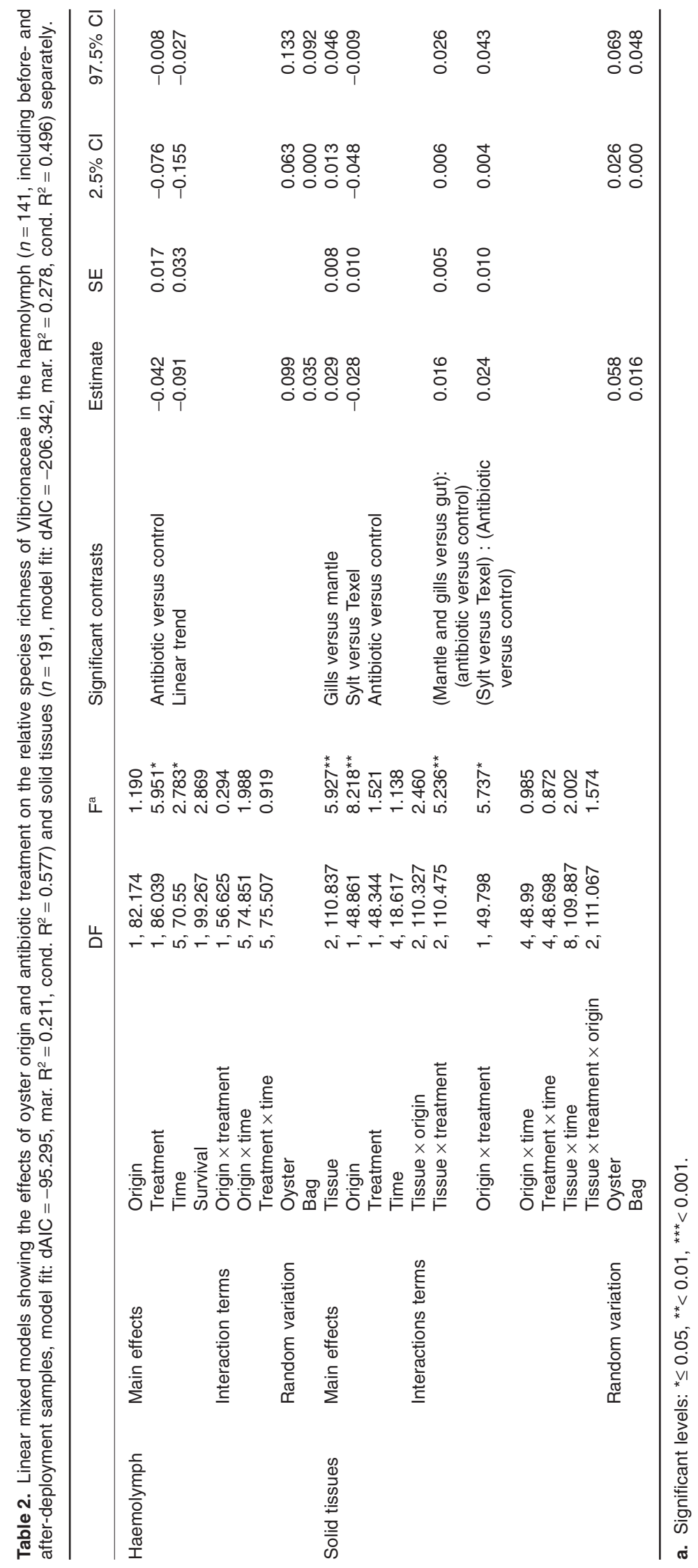

(C) 2015 Society for Applied Microbiology and John Wiley \& Sons Ltd, Environmental Microbiology 


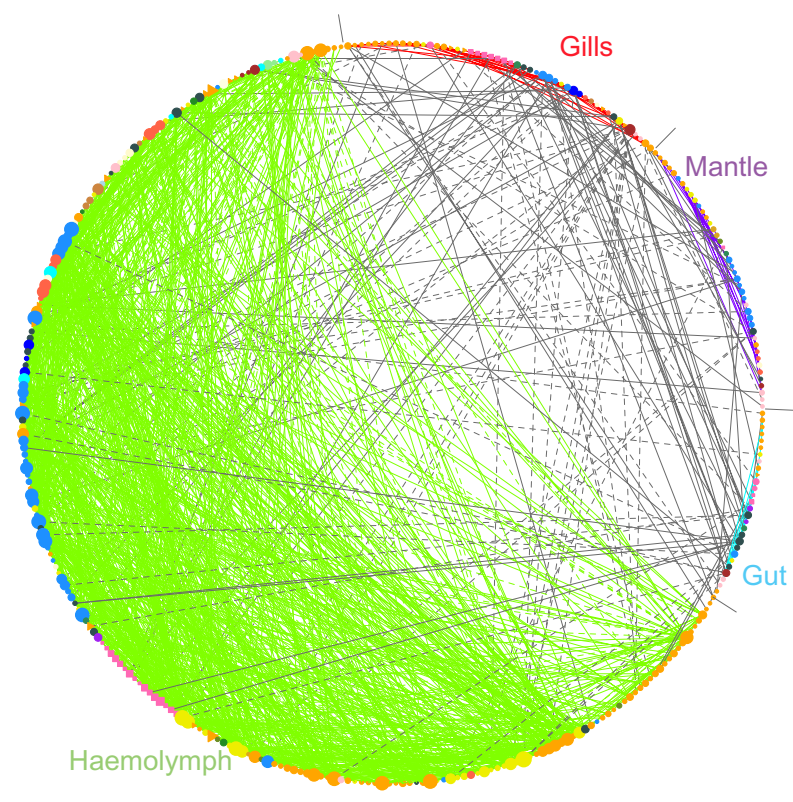

Fig. 5. Association network showing OTU relationships within and across the tissues. Nodes are coloured by taxonomy (as in Fig. 3 ) and the size is proportional to the node degree. Full line denotes co-occurrence, the dashed line denotes co-exclusion; edge weight is proportional to correlation strength. Colour of edges connecting OTUs within the tissue correspond to colour of that tissue; inter-tissue edges are grey.

connected modules, which resulted in a pronounced modular structure also reflected by a lower clustering coefficient.

\section{Discussion}

\section{Role of microbiota in oyster mortality}

Intentional (transport, cultivation) and unintentional (invasion) translocation exposes plants and animals to novel abiotic and biotic conditions. One example is exposure to new microbes colonizing hosts, where they interact not only with the host but also with its resident microbiota. High mortality of translocated oysters in our study may have been caused by such interactions, since resetting the microbial communities by administering antibiotics prior to the field deployment significantly reduced mortality in translocated hosts. Alternatively, the antibiotic treatment could have mitigated the effects of a transportstress-induced bacteriosis and affected mortality directly. Since we neither recorded any mortality during transport or in the initial lab-based rearing, nor could we detect any signs of previous disease or significant differences in immune parameters, we consider this to be unlikely. Genetically based direct interactions between hosts and new microbiota could also be excluded as a potential cause of mortality, as genotypes from both oyster populations (Moehler et al., 2011) were randomly distributed between the antibiotic treatments. The specific change in the network topology - observed in Texel but not in Sylt oysters (Fig. 6) - rather suggests that it was the indirect effects mediated by the resident haemolymph microbiota bacteria (eliminated by antibiotic treatment) and new specific environmental conditions - including the exposure to a new microbial context - that contributed to mortality (Rillig et al., 2015).

Whereas high vibrio load and diversity were observed in the haemolymph of all healthy oysters (including both control groups), they did not translate into high loads in the solid tissues or disease (Petton et al., 2015). High loads of active Vibrionaceae in solid tissues were observed only in translocated control animals and could represent signs of systemic infections and thus the proximate cause of mortality. This underlines the importance of performing tissue-specific analyses to understand how the microbiota affects its host.

\section{Interactions of haemolymph microbiota with the internal and external environment}

The inter-tissue OTU associations (Fig. 5) and fine-scale individual variation in community composition (compare UniFrac and Bray-Curtis in Fig. 4A) suggest that the oyster microbiome is shaped by genotype (Wegner et al., 2013), condition (Lokmer and Wegner, 2015) and neutral processes (Nemergut et al., 2013). However, the differences in community structure between the haemolymph and solid-tissue microbiota (Figs 2-5) indicate the prominent role of ecological and functional differences between the tissues (Costello et al., 2009; Fuhrman, 2009; Pontarp et al., 2012; Faust et al., 2015a). High network connectivity and the recurring core OTU subclusters (shared groups of OTUs in the networks in Fig. 6 and Fig. S2) imply that a considerable portion of haemolymph microbiota was unaffected by host origin and antibiotics, but rather determined by factors unaccounted for in our experimental design. These subclusters might represent OTU assemblages characteristic for alternative stable community states, possibly related to changes in oxygen concentration associated with periodical valve closing (Sow et al., 2011; Faust et al., 2012). High prevalence of aerobic, seawater-deduced bacteria in one subcluster, and the dominance of microaerobic or anaerobic species (Levican et al., 2014) in the other(s), might reflect a healthy microbiome's response to predictably recurring environmental conditions, i.e. to the tidal cycle (Relman, 2012; Faust et al., 2015b). Shifts in relative OTU abundance within genera (e.g. Arcobacter), combined with the persistent community composition at higher taxonomic levels, likely represent yet another mechanism by which the haemolymph microbiota contribute to oyster response to environmental conditions and/or reflect the oyster 


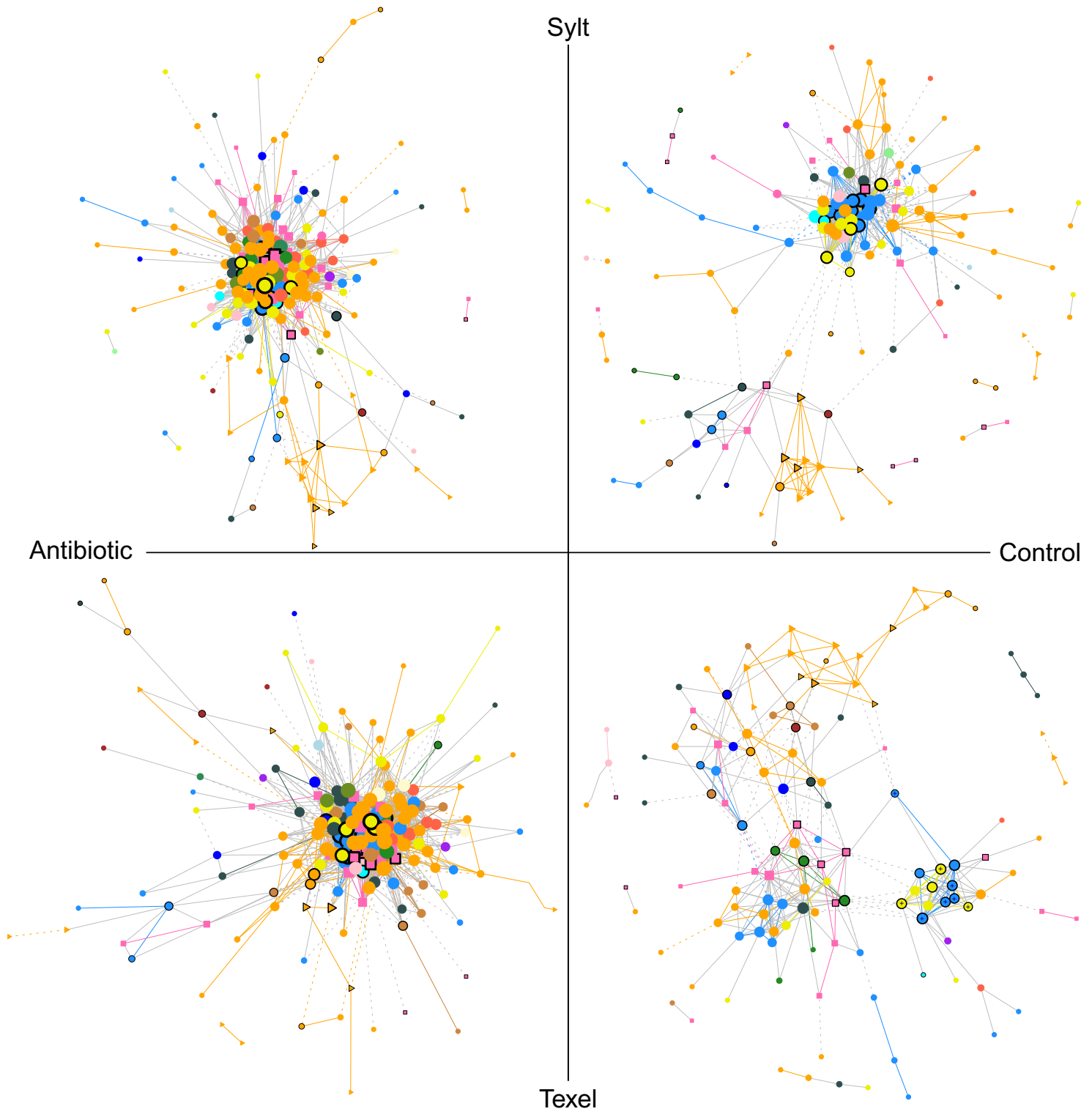

Fig. 6. Association networks of haemolymph OTUs grouped by oyster origin and treatment. Black frame denotes OTUs shared by all four networks. Nodes are coloured by taxonomy (as in Fig. 3) and the size is proportional to degree. Full line denotes co-occurrence, the dashed line denotes co-exclusion; edge weight is proportional to correlation strength. Edges connecting OTUs within the same class are coloured by taxonomy, else they are grey. $\triangle$ Vibrionaceae; $\square$ Arcobacter. In the last panel, mainly negative correlations between the subcluster with the core consisting mainly of OTUs abundant in the seawater (marked by ' + ') and the rest of OTUs are apparent (see also Fig. S2).

condition (Lokmer and Wegner, 2015). Overall, the community dynamics of haemolymph microbiota demonstrate its close connection to the internal and external oyster environment - a prerequisite for a role in acclimation and maintenance of homeostasis in highly dynamic environmental conditions.

\section{Haemolymph microbiota in response to translocation and antibiotic treatment}

Time lag between the antibiotic treatment and field deployment resulted in partial recovery and higher diver- sity of oyster microbiota, likely preventing deleterious effects of depleted microbial communities in the treated animals (Ridley et al., 2012; Abt and Pamer, 2014; Gorokhova et al., 2015). In addition, low evenness of haemolymph communities prior to deployment in the oysters that eventually died suggests that evenness can be used as an indicator for predicting disease (Ransome et al., 2014; Lokmer and Wegner, 2015). Therefore, the diversity of haemolymph microbiota seems to be important for a successful response of oysters to environmental challenges (Ptacnik et al., 2008; Wittebolle et al., 2009; Eisenhauer et al., 2012; Stenuit and Agathos, 2015). 
Table 3. Properties of the networks depicted in Fig. 6 .

\begin{tabular}{|c|c|c|c|c|}
\hline & \multicolumn{2}{|c|}{ Sylt } & \multicolumn{2}{|c|}{ Texel } \\
\hline & Control & Antibiotic & Control & Antibiotic \\
\hline \# Samples & 35 & 36 & 32 & 38 \\
\hline \# Nodes & 149 & 211 & 129 & 190 \\
\hline \# Edges & 721 & 2348 & 362 & 2742 \\
\hline$\%$ Positive edges & 82.1 & 61.1 & 85.4 & 56.7 \\
\hline Average degree & 9.678 & 22.256 & 5.612 & 28.863 \\
\hline Max degree & 49 & 94 & 24 & 93 \\
\hline \# Clusters & 12 & 5 & 7 & 2 \\
\hline Connectance & 0.065 & 0.106 & 0.044 & 0.153 \\
\hline Average path length & 3.331 & 2.693 & 3.604 & 2.417 \\
\hline Average betweenness centrality & 0.011 & 0.008 & 0.015 & 0.007 \\
\hline Modularity & 0.224 & 0.053 & 0.599 & 0.036 \\
\hline Global clustering coefficient & 0.625 & 0.540 & 0.459 & 0.565 \\
\hline
\end{tabular}

Detailed comparison with random networks can be found in Table S5.

Apart from diversity, oyster response to the stress exerted by our treatments could have been positively affected by increased co-occurrence network connectivity, which probably reflected higher robustness of haemolymph microbiota against disturbances (Estrada, 2007; Scheffer et al., 2012; Shade et al., 2012). Due to low resolution of 16 s rDNA-based analysis (Koeppel and Wu, 2012; Schmidt et al., 2014), we cannot distinguish if the increased connectivity was due to external colonization of the disturbed communities (Robinson et al., 2010) or to a correlated response of resident bacteria to antibiotics. Still, the higher diversity of antibiotic treated communities suggests increased external colonization because antibiotics usually decrease diversity due to dominance of few resistant strains (Manichanh et al., 2010; Dethlefsen and Relman, 2011; Panda et al., 2014), especially when administering a mix of antibiotics like performed here (Pena-Miller et al., 2013).

In control oysters from Texel, high modularity and lower clustering coefficients could indicate a decreased compensation capacity and thus a lower probability to successfully respond to disturbances (Yachi and Loreau, 1999). Although the exact processes behind the observed changes in community structure remain unclear, oysters as filter feeders are in constant touch with a multitude of bacteria, and intense microbial interactions in a new microbial context could have affected community stability (Defer et al., 2013; Rillig et al., 2015). Such destabilization of the haemolymph microbiota, caused, for example, by interactions between closely related but distinct strains (West and Buckling, 2003; Brown et al., 2009; Koskella et al., 2011; Wendling and Wegner, 2015) could explain the spillover of Vibrionaceae into solid tissues, resulting in a systemic disease and higher mortality of translocated control oysters.

However, the interpretation of the co-occurrence network topology is not straightforward and the ecological implications vary widely depending on the sort of input data and the network building criteria (Thebault and Fontaine, 2010; Faust and Raes, 2012; Berry and Widder, 2014; Widder et al., 2014; Williams et al., 2014; Faust et al., 2015a; Peura et al., 2015). In addition, the relationship between the stability and topology of the networks depends on the type of disturbances to which the studied communities are exposed to (Holme, 2011). Therefore, caution must be exerted when linking network structure to the mortalities observed here, unless network characteristics like connectivity and modularity are experimentally manipulated. Eliminating specific bacterial groups by narrow-spectrum antibiotics is one possibility to perform targeted manipulation of the network structure (Rea et al., 2011), and that could elucidate causal links between haemolymph community stability and tissue colonization by pathogens.

\section{Specificity of microbiota in solid tissues}

While high diversity of haemolymph microbiota likely reflects its tight connection to the variable environment, the lower diversity of gut or gill microbiota may reflect the specialized functional roles in target tissues (e.g. such as nutrition in the gut; Duperron et al., 2007; Fraune and Zimmer, 2008; Rodrigues et al., 2010; Fernandez-Piquer et al., 2012). Such tissue-specific functional specialization should lead to increased persistence of microbiota in solid tissues. Here, we mainly observed origin-related persistence of gill microbiota throughout the initial phase of colonization (Table S6). Gills show high bacterial activity in Pacific oysters (Hernandez-Zarate and Olmos-Soto, 2006) and many bivalve bacterial symbionts are situated there (Duperron et al., 2007; Dubilier et al., 2008; Rodrigues et al., 2010). Gill microbiota also exhibits longterm stability (Zurel et al., 2011) and its composition correlates with its host genotype (Wegner et al., 2013). While the differences observed here could represent carryover from the original site (Wegner et al., 2013; Trabal 
Fernandez et al., 2014) and would thus gradually disappear (Wendling et al., 2014; Meisterhans et al., 2015), their long-term persistence could reflect differences in the genetic structure and history of both oyster populations (Moehler et al., 2011).

\section{Conclusion}

We experimentally manipulated the interactions of the oyster holobiont with the environment on several levels, including the host genotype (by using genetically differentiated host populations), the resident microbiota (by administering antibiotics) and the external bacterial context (by translocating treated and untreated hosts). Our data highlight the importance to consider microbiota in a tissue-specific context in order to understand the interaction of the holobiont with a newly encountered environment. Specifically, the spillover of Vibrionaceae from the haemolymph into solid tissues and a resulting systemic disease seemed to depend on the structure and stability of haemolymph microbiota in response to a new microbial context. This signifies the prominent role of community structure and not necessarily taxonomic composition of the haemolymph microbiome for oyster homeostasis. In order to elucidate the processes behind the observed changes in community structure and to better understand the function of microbiota in different tissues, more studies focusing on the metabolism and physiology of functionally important symbionts within these dynamic bacterial networks are needed.

\section{Experimental procedures}

\section{Oyster collection and pretreatment}

To test interactions between the resident and novel external microbiota, we transplanted oysters from the Southern Wadden Sea to the Northern Wadden Sea and followed their survival and changes in microbial communities over a 5-day period. Southern Wadden Sea oysters $(n=40)$ were col-

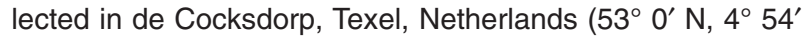
E), cleaned of epibionts and transported to the AWI Wadden Sea station on Sylt. The same number of oysters was collected from the transplantation site (Oddewatt, Sylt, Germany, $\left.55^{\circ} 1^{\prime} \mathrm{N}, 8^{\circ} 26^{\prime} \mathrm{E}\right)$. Initially, the oysters $(n=80)$ were kept in pre-filtered seawater from their original location at ambient temperature $\left(\sim 14^{\circ} \mathrm{C}\right)$. To remove parts of the resident microbiota, we added an antibiotic cocktail $\left(100 \mu \mathrm{g} \mathrm{l}^{-1}\right.$ of each ampicillin, tetracycline, gentamicin and kanamycine, Sigma-Aldrich, Hamburg, Germany) to half of the oysters from each location. The antibiotic concentrations were chosen based on previous tests, where we treated the oysters with the antibiotics and plated out haemolymph on marine agar until no colonies had grown. After 3 days, we took haemolymph samples from the adductor muscle with 23_1/4 gauge $(0.6 \mathrm{dm}, 30 \mathrm{~mm})$ needles via notches drilled on the ventral side of the shell immediately after collection (to give the oysters time to recover). We froze $\sim 200 \mu \mathrm{l}$ aliquots of haemolymph for microbiota analysis at $-80^{\circ} \mathrm{C}$, and immediately processed the rest of the sample to measure the immune parameters (THC, phagocytosis rate, haemolymph plasma protein concentration). To estimate the number of cultivable Vibrionaceae, we plated $5 \mu \mathrm{l}$ of haemolymph on TCBS agar and counted the resulting CFU.

\section{Experimental set-up and sampling}

The pretreatment resulted in four groups, each containing 20 animals: translocated (antibiotic)-treated, translocated control, non-translocated (antibiotic)-treated and nontranslocated control oysters (Fig. 1A). For the field transplant, always four oysters (one from each group) were put into a single bag with a mesh size of $1 \mathrm{~cm}$, resulting in 20 bags that were brought out to the original site of collection of the northern Wadden Sea oysters (Odewatt). For the following 5 days, we randomly collected four bags every day. The period of 5 days was chosen because we wanted to focus on the initial phase of the establishment, where we assumed the most drastic and influential changes in the microbiome would occur based on the previous infection experiments (Lokmer and Wegner, 2015). We checked the survival and dissected the surviving oysters, after taking a haemolymph sample through the predrilled hole. We cut around $25 \mathrm{~mm}^{3}(\sim 100 \mathrm{mg}$ wet weight) of the mantle, gills and gut tissues with a sterile knife and flushed them thoroughly with sterile PBS in order to remove transient, non-attached bacteria. We immediately froze half of the tissue for microbiota analysis at $-80^{\circ} \mathrm{C}$, while the other half was used to determine the number of cultivable Vibrionaceae. To do so, we homogenized the tissue pieces in $500 \mu$ of sterile PBS in the Qiagen TissueLyser (Hilden, Germany) using a single $5 \mathrm{~mm}$ stainless steel bead at $20 \mathrm{~Hz}$ for $3 \mathrm{~min}$ and plated $10 \mu \mathrm{l}$ on TCBS agar.

To determine the background composition of the microbial communities and the number of cultivable Vibrionaceae in the seawater, we took seawater samples $(100 \mathrm{ml})$ on three occasions during the sampling period (six samples in total, three of them sequenced). The samples were filtered onto $0.2 \mu \mathrm{m}$ $47 \mathrm{~mm}$ Nuclepore Track-Etch Membrane filters, which were then used for DNA extraction.

\section{Oyster immune parameters}

In order to measure THC, $50 \mu$ l of haemolymph was mixed with equal amounts of $6 \%$ formaldehyde in sterile seawater (SSW) and marine anticoagulant solution (Fedders and Leippe, 2008). The resulting solution was further diluted $3 \times$ in sterile PBS and the cell count was measured with an automated cell counter (Scepter, Millipore, Darmstadt, Germany).

For phagocytosis, we followed the established protocols (Wendling and Wegner, 2013). In short, $3 \times 60 \mu \mathrm{l}$ of haemolymph were allowed to adhere to the bottom of 96-well plates for $1 \mathrm{~h}$. The supernatant was carefully decanted, and the neutral-red-stained zymosan solution (Sigma-Aldrich) was added to haemocytes and incubated with shaking for $1 \mathrm{~h}$. The reaction was stopped by the addition of $6 \%$ formol in SSW. The wells were washed several times with PBS, the haemocytes with the phagocytosed particles were solubilized in acidified ethanol ( $1 \%$ acetic acid, $50 \%$ ethanol), and the 
absorbance was measured at $550 \mathrm{~nm}$ with Nanodrop ND-1000 spectrometer (peqlab, Erlangen, Germany). The standard curve was constructed from zymosan solution samples with known particle concentration, and the results were expressed as the number of phagocytosed particles per haemocyte.

To estimate the plasma protein content, $200 \mu \mathrm{l}$ of haemolymph was centrifuged for $5 \mathrm{~min}$ at $5000 \mathrm{~g}$. The protein concentration in the supernatant was measured in triplicates with Quick-Start Bradford protein Bio-Assay (Bio-Rad, Hercules, CA, USA) according to the manufacturer's protocol.

\section{DNA extraction}

DNA was extracted from approximately $200 \mu \mathrm{l}$ of haemolymph, or approximately $50 \mathrm{mg}$ of mantle, gill and gut tissue with Wizard SV 96 Genomic DNA Purification System (Promega, Mannheim, Germany). The samples were placed in pre-cooled $\left(-20^{\circ} \mathrm{C}\right)$ TissueLyser Adapters (Qiagen) and homogenized in a mixer mill (Retsch, Haan, Germany), using a mixture of $0.5 \mathrm{~mm}$ glass-zirconium beads and a single $5 \mathrm{~mm}$ tungsten bead (for mantle, gill and gut) or $1 \mathrm{~mm}$ glass beads (for haemolymph) at $30 \mathrm{~Hz}$ for $5 \mathrm{~min}$ in order to completely disrupt the tissues and bacterial cells. The standard protocol for DNA extraction from animal tissues was used for mantle, gill and tissue, while only proteinase $\mathrm{K}(20 \mu \mathrm{l}$ of $20 \mathrm{mg} \mathrm{ml}^{-1}$ solution, Sigma-Aldrich) was added to the haemolymph for protein digestion. The samples were incubated at $55^{\circ} \mathrm{C}$ for at least $4 \mathrm{~h}$ and extracted according to the manufacturer's protocols. Blank extractions to check for bacterial contamination of reagents were also performed.

For the seawater samples, the filters were cut with sterile scissors into smaller pieces and homogenized in $2 \mathrm{ml}$ tubes with a mixture of beads from PowerWater® DNA Isolation Kit (MO BIO Laboratories, Carlsbad, CA, USA) and $0.5 \mathrm{~mm}$ glass-zirconium beads in RLT buffer (DNeasy Blood \& Tissue Kit, Qiagen) and further treated as described in Thomsen and colleagues (2012). Shortly, a round of bead beating at $30 \mathrm{~Hz}$ for $5 \mathrm{~min}$ was followed by $10 \mathrm{~min}$ at $56^{\circ} \mathrm{C}$ with continuous mixing. This was repeated twice and then the proteinase $\mathrm{K}$ was added and the digestion mix was incubated for $2 \mathrm{~h}$. The samples were then extracted following the manufacturer's protocol with the adjusted reagent volumes. We used different methods for DNA extraction from the seawater and oyster tissues due to the differing properties of the source material. Although this could introduce a bias and caution is required in interpreting the results, previous research has shown that such biases tend to be minor (Sergeant et al., 2012; Rubin et al., 2014).

\section{Polymerase chain reaction (PCR)}

We amplified 16s rRNA V1-V2 regions with uniquely barcoded $27 \mathrm{f}$ and $338 \mathrm{r}$ PCR primers. The PCR reactions $(25 \mu \mathrm{l})$ were set up in 96-well plates as follows: $4 \mu \mathrm{l}$ of each forward and reverse primer (final concentration: $0.28 \mu \mathrm{M}$ ), $0.5 \mu \mathrm{l}$ dNTPs (final concentration: $200 \mu \mathrm{M}$ each), $0.25 \mu \mathrm{l}$ Phusion Hot Start II High-Fidelity DNA Polymerase (0.5 unit per reaction) and $5 \mu \mathrm{l}$ of High fidelity (HF) buffer $(7.5 \mathrm{mM}$ $\mathrm{MgCl} 2$, Thermo Fisher Scientific, Waltham, MA, USA). We used $1 \mu \mathrm{l}$ of undiluted haemolymph DNA, $1 \mu \mathrm{l}$ of $10 \times$ diluted seawater DNA and 2-4 $\mu$ l of solid tissue DNA per reaction. For each 96-well plate, 20 control reactions $(12.5 \mu \mathrm{l})$ were performed: one positive control and unique combinations of all used forward and reverse primers as negative control, with water as a template.

The PCR cycling conditions were as follows: $30 \mathrm{~s}$ initial denaturation at $98^{\circ} \mathrm{C}$, then 30 cycles: $9 \mathrm{~s}$ denaturation at $98^{\circ} \mathrm{C}, 1 \mathrm{~min}$ annealing at $55^{\circ} \mathrm{C}, 90 \mathrm{~s}$ extension at $72^{\circ} \mathrm{C}$, $10 \mathrm{~min}$ final extension at $72^{\circ} \mathrm{C}$.

In order to check for the product and to estimate its amount, the reactions were analysed immediately on a $1.5 \%$ agarose gel. Briefly, $5 \mu$ l of loading buffer was mixed with $3 \mu$ reaction and loaded into the gel prepared with SYBR Safe DNA Gel Stain (Life Technologies $\mathrm{GmbH}$, Darmstadt, Germany), including $3 \mu \mathrm{l}$ of O'GeneRuler ${ }^{\mathrm{TM}} 100 \mathrm{bp}$ Plus DNA Ladder (Thermo Fisher Scientific). The separation was conducted at $120 \mathrm{~V}$ per $35 \mathrm{~cm}$ for $80 \mathrm{~min}$. The result was photographed with Gel Doc ${ }^{\mathrm{TM}}$ XR+ System and analysed with Image Lab ${ }^{\mathrm{TM}}$ Software (Bio-Rad) to estimate the absolute concentration of the PCR products using the ruler as internal standard. If there was no amplification in blank extractions, they were excluded from further analysis. Equal amounts of the products from a single gel were pooled together (25-100 ng per sample), run on $1.5 \%$ agarose gel and purified with MinElute Gel Extraction Kit (Qiagen) according to the manufacturer's protocol, including optional additional centrifugation and steps recommended for salt-sensitive applications. The concentration of DNA in the resulting subpools was measured fluorometrically with Qubit dsDNA br Assay Kit (Life Technologies $\mathrm{GmbH}$ ) in the Qubit fluorometer (Life Technologies Invitrogen Gmbh, Karlsruhe, Germany). The equal amounts of subpools were then mixed together and frozen at $-20^{\circ} \mathrm{C}$ until sequencing. The paired-end sequencing by synthesis was performed on an Illumina MiSeq platform at the Max Planck Institute for Evolutionary Biology in Plön, Germany.

\section{Sequence quality control and preprocessing}

All sequencing libraries were processed together. Quality control, OTU clustering and taxonomy assignment were performed in MOTHUR (Schloss et al., 2009), following the MothUR MiSeq SOP (Kozich et al., 2013). We retained only overlapping regions of the contigs and removed any sequences with ambiguous bases and/or homopolymers of $8 \mathrm{bp}$ or longer in order to ensure good quality and reduce the number of spurious OTUs. The sequences were aligned to SILVA 119 reference alignment (Quast et al., 2013) cut to $\mathrm{V} 1-\mathrm{V} 2$ region, and the taxonomy was assigned with $80 \%$ confidence cut-off, using the Greengenes taxonomy 13_08 (DeSantis et al., 2006) and the Naïve Bayesian Classifier (Wang et al., 2007) implemented in MotHuR. Unknown (i.e. sequences not assigned to any kingdom), chloroplast, Archaea and Eukaryotic sequences were removed from further analysis. We performed single-linkage pre-clustering with two differences allowed (Huse et al., 2010), removed the chimeras and created $97 \%$ OTUs using average-linkage clustering method. Consensus taxonomy for an OTU was assigned with a $50 \%$ consensus confidence threshold. We calculated rarefaction curves of diverse $\alpha$-diversity metrics in QIIME (Caporaso et al., 2010) in order to estimate the effect of sampling effort and to determine sequencing depth for the 
final analysis. We subsampled the dataset to 8000 reads per sample for the final analysis. Because the abundant OTUs $(>100$ reads) in the single positive blank control were rare $(<1 \%)$ in the remaining samples, we simply excluded them from further analysis. In order to calculate a tree needed for phylogenetic measures of diversity, we picked a representative set of sequences using the distance method in MOTHUR and calculated the tree using FASTREE (Price et al., 2010). The final dataset comprised 3 seawater, 141 haemolymph (including pre- and post-deployment samples), 68 gill, 61 gut and 62 mantle samples (335 in total).

\section{Statistical analysis}

All statistical analyses were performed in $\mathrm{R}$ ( $\mathrm{R}$ Core Team, 2013). For $\alpha$-diversity, we used a complete rarified dataset (8000 reads per sample) to analyse the differences in evenness [calculated as $\mathrm{H} / \mathrm{In}(\mathrm{S})$, where $\mathrm{H}$ is the Shannon-Wiener index and $S$ is species richness] and species richness (total number of species). We first tested for differences between the seawater and oysters using non-parametric asymptotic Wilcoxon Mann-Whitney RS test (Wilcoxon RS test). We subsequently tested for differences between the tissues using robust analysis of variance (Wilcox and Schönbrodt, 2014), as the assumptions for classical ANOVA were not satisfied. Finally, we analysed haemolymph and solid tissues separately with linear mixed models (Bartoń, 2014; Kuznetsova et al., 2015; Bates et al., 2015).

Because not only Vibrio sp. but also other Vibrionaceae grow on TCBS agar and, in addition, classification of short reads to low taxonomic levels can be unreliable, we decided to focus the analyses on the whole Vibrionaceae family, and not just the genus Vibrio. In addition, due to the sampling procedure, the CFU counts were not directly comparable between the haemolymph and solid tissues, and were thus analysed separately.

For $\beta$-diversity, we kept only the OTUs with relative abundance higher than $0.1 \%$ in at least 10 samples to reduce the dataset complexity. We calculated Bray-Curtis distances and weighted UniFrac distances (Hamady et al., 2010) using the phyloseq package (McMurdie and Holmes, 2013), and the results were further analysed by NMDS and Permanova (non-parametric permutational multivariate analysis of variance; Anderson and Beaven, 2001) implemented in the adonis function in the vegan package (Oksanen et al., 2013). We first compared the tissues and then analysed the $\beta$-diversity in each tissue separately.

We statistically examined the variation at the class-level taxonomical composition between the tissues and the changes in the abundance of OTUs and genera in haemolymph microbiota according to origin and treatment by multivariate generalized mixed models (mvabund package; Wang et al., 2012). This method fits a multivariate model for the differences between the whole communities as well as univariate models for the abundance of each taxon separately, thus identifying taxa responsible for the observed differences. Because the mean-variance relationship of the data is empirically estimated prior to the model-fitting (in this case negativebinomial), potential confounding of location and dispersion effects inherent to distance-based methods is avoided (Warton et al., 2012).
We included time as an ordered factor in the models to check for temporal trends in the data. However, we could not disentangle individual variability from true time effects due to our experimental design. For this reason we do not further discuss the temporal trends, although we included them in results for completeness.

To explore both positive and negative associations of the OTUs within and between the tissues, we constructed an association network using the sparcc algorithm (Friedman and Alm, 2012) implemented in MOTHUR. We performed 10000 permutations and kept only correlations $>0.4$ with $P$ value $<10^{-4}$ to exclude as many spurious correlations as possible (Marino et al., 2014). The input matrix was organized similar to Faust and colleagues (2012): OTUs in tissues in the rows and individual oysters in columns. Only the oysters with available data for all four tissues and the OTUs that appeared in at least one third of the samples were analysed (Berry and Widder, 2014). We statistically determined the significance of observed connectivity within/ between the tissues by comparison to connectivity between the random subsets of nodes of equal size as the tested group (Faust et al., 2012). Additionally, to assess the effect of treatment and origin on microbial associations in the haemolymph, we constructed a network for each experimental group of oysters including only haemolymph samples, and calculated their descriptive statistics including clustering coefficient (Newman et al., 2002) and modularity. Modularity is a measure of separation of a network into densely intraconnected areas, with fewer connections between them (modules, communities), with respect to some division rule. In this case modules were computed using the walktrap algorithm (Pons and Latapy, 2005). The networks were visualized using the igraph package (Csardi and Nepusz, 2006). Raw demultiplexed sequence data are available at European Nucleotide Archive under the study accession number PRJEB8492.

\section{Acknowledgements}

We would like to thank Anouk Goedknegt for collecting the oysters on Texel and their transport to Sylt, Laura Burbaum, Silke Vollbrecht and Franziska Schade for their help with sampling and dissections, Tobias Mayr for cleaning the oysters, and Katja Cloppenborg-Schmidt at the Evolutionary Genomics group at Kiel University for assistance with the preparation of MiSeq libraries. This study was supported by the DFG (Deutsche Forschungsgemeinschaft) Emmy Noether Programme (We4641/1-3), Excellence Cluster 306 'Inflammation at Interfaces', and the International Max Planck Research School for Evolutionary Biology.

\section{References}

Abt, M.C., and Pamer, E.G. (2014) Commensal bacteria mediated defenses against pathogens. Curr Opin Immunol 29: 16-22.

Anderson, R., and Beaven, A. (2001) Antibacterial activities of oyster (Crassostrea virginica) and mussel (Mytilus edulis and Geukensia demissa) plasma. Aquat Living Resour 14: 343-349. 
Antunes, F., Hinzmann, M., Lopes-Lima, M., Machado, J., and da Costa, P.M. (2010) Association between environmental microbiota and indigenous bacteria found in hemolymph, extrapallial fluid and mucus of Anodonta cygnea (Linnaeus, 1758). Microb Ecol 60: 304309.

Bartoń, K. (2014) MuMln: multi-model inference. R package version 1.10.5. URL http://CRAN.R-project.org/ package $=$ MuMIn .

Bates, D., Maechler, M., Bolker, B.M., and Walker, S. (2015) Fitting linear mixed-effects models using Ime4. J Stat Softw URL http://arxiv.org/abs/1406.5823.

Bauvais, C., Zirah, S., Piette, L., Chaspoul, F., DomartCoulon, I., Chapon, V., et al. (2015) Sponging up metals: bacteria associated with the marine sponge Spongia officinalis. Mar Environ Res 104: 20-30.

Beleneva, I.A., Zhukova, N.V., Lan, H., and Nguyen Tran, D.H. (2007) Taxonomic composition of bacteria associated with cultivated mollusks Crassostrea lugubris and Perna viridis and with the water of the Gulf of Nha Trang lagoon, Vietnam. Microbiology 76: 220-228.

Berry, D., and Widder, S. (2014) Deciphering microbial interactions and detecting keystone species with co-occurrence networks. Front Microbiol 5: 219.

Brown, S.P., Fredrik Inglis, R., and Taddei, F. (2009) Evolutionary ecology of microbial wars: within-host competition and (incidental) virulence. Evol Appl 2: 32-39.

Caporaso, J.G., Kuczynski, J., Stombaugh, J., Bittinger, K., Bushman, F.D., Costello, E.K., et al. (2010) QIIME allows analysis of high-throughput community sequencing data. Nat Methods 7: 335-336.

Cohan, F.M., and Koeppel, A.F. (2008) The origins of ecological diversity in prokaryotes. Curr Biol 18: R1024R1034.

Costello, E.K., Lauber, C.L., Hamady, M., Fierer, N., Gordon, J.I., and Knight, R. (2009) Bacterial community variation in human body habitats across space and time. Science 326: 1694-1697.

Csardi, G., and Nepusz, T. (2006) The igraph software package for complex network research. InterJ Complex Syst 1695: 1695.

David, L.A., Materna, A.C., Friedman, J., Campos-Baptista, M.I., Blackburn, M.C., Perrotta, A., et al. (2014) Host lifestyle affects human microbiota on daily timescales. Genome Biol 15: R89.

Defer, D., Desriac, F., Henry, J., Bourgougnon, N., BaudyFloc'h, M., Brillet, B., et al. (2013) Antimicrobial peptides in oyster hemolymph: the bacterial connection. Fish Shellfish Immunol 34: 1439-1447.

Desriac, F., Le Chevalier, P., Brillet, B., Leguerinel, I., Thuillier, B., Paillard, C., and Fleury, Y. (2014) Exploring the hologenome concept in marine bivalvia: haemolymph microbiota as a pertinent source of probiotics for aquaculture. FEMS Microbiol Lett 350: 107-116.

DeSantis, T.Z., Hugenholtz, P., Larsen, N., Rojas, M., Brodie, E.L., Keller, K., et al. (2006) Greengenes, a chimera-checked 16S rRNA gene database and workbench compatible with ARB. Appl Environ Microbiol 72: 5069-5072.

Dethlefsen, L., and Relman, D.A. (2011) Incomplete recovery and individualized responses of the human distal gut microbiota to repeated antibiotic perturbation. Proc Natl Acad Sci USA 108 (Suppl. 1): 4554-4561.

Dubilier, N., Bergin, C., and Lott, C. (2008) Symbiotic diversity in marine animals: the art of harnessing chemosynthesis. Nat Rev Microbiol 6: 725-740.

Duperron, S., Fiala-Medioni, A., Caprais, J.C., Olu, K., and Sibuet, M. (2007) Evidence for chemoautotrophic symbiosis in a Mediterranean cold seep clam (Bivalvia: Lucinidae): comparative sequence analysis of bacterial $16 S$ rRNA, APS reductase and RubisCO genes. FEMS Microbiol Ecol 59: 64-70.

Eisenhauer, N., Scheu, S., and Jousset, A. (2012) Bacterial diversity stabilizes community productivity. PLOS ONE 7: e34517.

Elston, R.A., Hasegawa, H., Humphrey, K.L., Polyak, I.K., and Hase, C.C. (2008) Re-emergence of Vibrio tubiashii in bivalve shellfish aquaculture: severity, environmental drivers, geographic extent and management. Dis Aquat Organ 82: 119-134.

Estrada, E. (2007) Food webs robustness to biodiversity loss: the roles of connectance, expansibility and degree distribution. J Theor Biol 244: 296-307.

Faust, K., and Raes, J. (2012) Microbial interactions: from networks to models. Nat Rev Microbiol 10: 538-550.

Faust, K., Sathirapongsasuti, J.F., Izard, J., Segata, N., Gevers, D., Raes, J., and Huttenhower, C. (2012) Microbial co-occurrence relationships in the human microbiome. PLoS Comput Biol 8: e1002606.

Faust, K., Lima-Mendez, G., Lerat, J.S., Sathirapongsasuti, J.F., Knight, R., Huttenhower, C., et al. (2015a) Crossbiome comparison of microbial association networks. Front Microbiol 6: 1200.

Faust, K., Lahti, L., Gonze, D., de Vos, W.M., and Raes, J. (2015b) Metagenomics meets time series analysis: unraveling microbial community dynamics. Curr Opin Microbiol 25: 56-66.

Fedders, H., and Leippe, M. (2008) A reverse search for antimicrobial peptides in Ciona intestinalis: identification of a gene family expressed in hemocytes and evaluation of activity. Dev Comp Immunol 32: 286-298.

Fernandez-Piquer, J., Bowman, J.P., Ross, T., and Tamplin, M.L. (2012) Molecular analysis of the bacterial communities in the live Pacific oyster (Crassostrea gigas) and the influence of postharvest temperature on its structure. $J$ Appl Microbiol 112: 1134-1143.

Ferreira, C.M., Vieira, A.T., Vinolo, M.A., Oliveira, F.A., Curi, R., and Martins Fdos, S. (2014) The central role of the gut microbiota in chronic inflammatory diseases. J Immunol Res 2014: 689492.

Fraune, S., and Zimmer, M. (2008) Host-specificity of environmentally transmitted Mycoplasma-like isopod symbionts. Environ Microbiol 10: 2497-2504.

Friedman, J., and Alm, E.J. (2012) Inferring correlation networks from genomic survey data. PLoS Comput Biol 8: e1002687.

Fuhrman, J.A. (2009) Microbial community structure and its functional implications. Nature 459: 193-199.

Galil, B.S., Marchini, A., Occhipinti-Ambrogi, A., Minchin, D., Narscius, A., Ojaveer, H., and Olenin, S. (2014) International arrivals: widespread bioinvasions in European Seas. Ethol Ecol Evol 26: 152-171. 
Garnier, M., Labreuche, Y., Garcia, C., Robert, M., and Nicolas, J.L. (2007) Evidence for the involvement of pathogenic bacteria in summer mortalities of the Pacific oyster Crassostrea gigas. Microb Ecol 53: 187-196.

Gorokhova, E., Rivetti, C., Furuhagen, S., Edlund, A., Ek, K., and Breitholtz, M. (2015) Bacteria-mediated effects of antibiotics on Daphnia nutrition. Environ Sci Technol 49: 57795787.

Hamady, M., Lozupone, C., and Knight, R. (2010) Fast UniFrac: facilitating high-throughput phylogenetic analyses of microbial communities including analysis of pyrosequencing and PhyloChip data. ISME J 4: 17-27.

Hedge, L.H., and Johnston, E.L. (2014) Colonisation of the non-indigenous Pacific oyster Crassostrea gigas determined by predation, size and initial settlement densities. PLOS ONE 9: e90621.

Hernandez-Zarate, G., and Olmos-Soto, J. (2006) Identification of bacterial diversity in the oyster Crassostrea gigas by fluorescent in situ hybridization and polymerase chain reaction. J Appl Microbiol 100: 664-672.

Hoffmann, M., Fischer, M., Ottesen, A., McCarthy, P.J., Lopez, J.V., Brown, E.W., and Monday, S.R. (2010) Population dynamics of Vibrio spp. associated with marine sponge microcosms. ISME J 4: 1608-1612.

Holme, P. (2011) Metabolic robustness and network modularity: a model study. PLOS ONE 6: e16605.

Hulcr, J., Latimer, A.M., Henley, J.B., Rountree, N.R., Fierer, N., Lucky, A., et al. (2012) A jungle in there: bacteria in belly buttons are highly diverse, but predictable. PLOS ONE 7: e47712.

Huse, S.M., Welch, D.M., Morrison, H.G., and Sogin, M.L. (2010) Ironing out the wrinkles in the rare biosphere through improved OTU clustering. Environ Microbiol 12: 1889-1898.

Jones, E.I., and Gomulkiewicz, R. (2012) Biotic interactions, rapid evolution, and the establishment of introduced species. Am Nat 179: E28-E36.

Kamada, N., Chen, G.Y., Inohara, N., and Nunez, G. (2013a) Control of pathogens and pathobionts by the gut microbiota. Nat Immunol 14: 685-690.

Kamada, N., Seo, S.U., Chen, G.Y., and Nunez, G. (2013b) Role of the gut microbiota in immunity and inflammatory disease. Nat Rev Immunol 13: 321-335.

King, G.M., Judd, C., Kuske, C.R., and Smith, C. (2012) Analysis of stomach and gut microbiomes of the eastern oyster (Crassostrea virginica) from coastal Louisiana, USA. PLOS ONE 7: e51475.

Kochmann, J., Buschbaum, C., Volkenborn, N., and Reise, K. (2008) Shift from native mussels to alien oysters: differential effects of ecosystem engineers. J Exp Mar Biol Ecol 364: 1-10.

Koeppel, A.F., and Wu, M. (2012) Lineage-dependent ecological coherence in bacteria. FEMS Microbiol Ecol 81: 574-582.

Koskella, B., Thompson, J.N., Preston, G.M., and Buckling, A. (2011) Local biotic environment shapes the spatial scale of bacteriophage adaptation to bacteria. Am Nat 177: 440451.

Kozich, J.J., Westcott, S.L., Baxter, N.T., Highlander, S.K., and Schloss, P.D. (2013) Development of a dual-index sequencing strategy and curation pipeline for analyzing amplicon sequence data on the MiSeq Illumina sequencing platform. Appl Environ Microbiol 79: 51125120.

Kuznetsova, A., Brockhoff, P.B., and Christensen, R.H.B. (2015) ImerTest: tests in linear mixed effects models. R package version 2.0-29. URL http://CRAN.R-project.org/ package=ImerTest.

Levican, A., Collado, L., Yustes, C., Aguilar, C., and Figueras, M.J. (2014) Higher water temperature and incubation under aerobic and microaerobic conditions increase the recovery and diversity of Arcobacter spp. from shellfish. Appl Environ Microbiol 80: 385-391.

Lokmer, A., and Wegner, K.M. (2015) Hemolymph microbiome of Pacific oysters in response to temperature, temperature stress and infection. ISME $J$ 9: 670682.

McMurdie, P.J., and Holmes, S. (2013) phyloseq: an R package for reproducible interactive analysis and graphics of microbiome census data. PLOS ONE 8: e61217.

Manichanh, C., Reeder, J., Gibert, P., Varela, E., Llopis, M., Antolin, M., et al. (2010) Reshaping the gut microbiome with bacterial transplantation and antibiotic intake. Genome Res 20: 1411-1419.

Marino, S., Baxter, N.T., Huffnagle, G.B., Petrosino, J.F., and Schloss, P.D. (2014) Mathematical modeling of primary succession of murine intestinal microbiota. Proc Natl Acad Sci USA 111: 439-444.

Martiny, J.B., Bohannan, B.J., Brown, J.H., Colwell, R.K., Fuhrman, J.A., Green, J.L., et al. (2006) Microbial biogeography: putting microorganisms on the map. Nat Rev Microbiol 4: 102-112.

Meisterhans, G., Raymond, N., Girault, E., Lambert, C., Bourrasseau, L., de Montaudouin, X., et al. (2015) Structure of Manila clam (Ruditapes philippinarum) microbiota at the organ scale in contrasting sets of individuals. Microb Ecol 71: 194-206.

Moehler, J., Wegner, K.M., Reise, K., and Jacobsen, S. (2011) Invasion genetics of Pacific oyster Crassostrea gigas shaped by aquaculture stocking practices. J Sea Res 66: 256-262.

Muehlbauer, F., Fraser, D., Brenner, M., Van Nieuwenhove, K., Buck, B.H., Strand, O., et al. (2014) Bivalve aquaculture transfers in Atlantic Europe. Part A: transfer activities and legal framework. Ocean Coast Manag 89: 127-138.

Nemergut, D.R., Schmidt, S.K., Fukami, T., O'Neill, S.P., Bilinski, T.M., Stanish, L.F., et al. (2013) Patterns and processes of microbial community assembly. Microbiol Mol Biol Rev 77: 342-356.

Newman, M.E., Watts, D.J., and Strogatz, S.H. (2002) Random graph models of social networks. Proc Natl Acad Sci USA 99 (Suppl. 1): 2566-2572.

Oksanen, J., Blanchet, F.G., Kindt, R., Legendre, P., Minchin, P.R., O'Hara, R.B., et al. (2013) vegan: community ecology package. URL http://CRAN.R-project.org/package=vegan.

Panda, S., El khader, I., Casellas, F., Lopez Vivancos, J., Garcia Cors, M., Santiago, A., et al. (2014) Short-term effect of antibiotics on human gut microbiota. PLOS ONE 9: e95476.

Pena-Miller, R., Laehnemann, D., Jansen, G., FuentesHernandez, A., Rosenstiel, P., Schulenburg, H., and Beardmore, R. (2013) When the most potent combination 
of antibiotics selects for the greatest bacterial load: the smile-frown transition. PLoS Biol 11: e1001540.

Petton, B., Bruto, M., James, A., Labreuche, Y., AlunnoBruscia, M., and Le Roux, F. (2015) Crassostrea gigas mortality in France: the usual suspect, a herpes virus, may not be the killer in this polymicrobial opportunistic disease. Front Microbiol 6: 686.

Peura, S., Bertilsson, S., Jones, R.I., and Eiler, A. (2015) Resistant microbial co-occurrence patterns inferred by network topology. Appl Environ Microbiol 81: 2090-2097.

Pita, L., Erwin, P.M., Turon, X., and Lopez-Legentil, S. (2013) Till death do us part: stable sponge-bacteria associations under thermal and food shortage stresses. PLOS ONE 8: e80307.

Pons, P., and Latapy, M. (2005) Computing communities in large networks using random walks. Lect Notes Comput Sci 3733: 284-293.

Pontarp, M., Canback, B., Tunlid, A., and Lundberg, P. (2012) Phylogenetic analysis suggests that habitat filtering is structuring marine bacterial communities across the globe. Microb Ecol 64: 8-17.

Price, M.N., Dehal, P.S., and Arkin, A.P. (2010) FastTree 2 approximately maximum-likelihood trees for large alignments. PLOS ONE 5: e9490.

Ptacnik, R., Solimini, A.G., Andersen, T., Tamminen, T., Brettum, P., Lepisto, L., et al. (2008) Diversity predicts stability and resource use efficiency in natural phytoplankton communities. Proc Natl Acad Sci USA 105: 51345138.

Quast, C., Pruesse, E., Yilmaz, P., Gerken, J., Schweer, T., Yarza, P., et al. (2013) The SILVA ribosomal RNA gene database project: improved data processing and webbased tools. Nucleic Acids Res 41: D590-D596.

$\mathrm{R}$ Core Team (2013) R: A Language and Environment for Statistical Computing. Vienna, Austria: R Foundation for Statistical Computing.

Ransome, E., Rowley, S.J., Thomas, S., Tait, K., and Munn, C.B. (2014) Disturbance to conserved bacterial communities in the cold-water gorgonian coral Eunicella verrucosa. FEMS Microbiol Ecol 90: 404-416.

Rea, M.C., Dobson, A., O'Sullivan, O., Crispie, F., Fouhy, F., Cotter, P.D., et al. (2011) Effect of broad- and narrowspectrum antimicrobials on Clostridium difficile and microbial diversity in a model of the distal colon. Proc Natl Acad Sci USA 108 (Suppl. 1): 4639-4644.

Relman, D.A. (2012) The human microbiome: ecosystem resilience and health. Nutr Rev 70 (Suppl. 1): S2-S9.

Ridley, E.V., Wong, A.C., Westmiller, S., and Douglas, A.E. (2012) Impact of the resident microbiota on the nutritional phenotype of Drosophila melanogaster. PLOS ONE 7: e36765.

Rillig, M.C., Antonovics, J., Caruso, T., Lehmann, A., Powell, J.R., Veresoglou, S.D., and Verbruggen, E. (2015) Interchange of entire communities: microbial community coalescence. Trends Ecol Evol 30: 470-476.

Robinson, C.J., Schloss, P., Ramos, Y., Raffa, K., and Handelsman, J. (2010) Robustness of the bacterial community in the cabbage white butterfly larval midgut. Microb Ecol 59: 199-211.

Rodrigues, C.F., Webster, G., Cunha, M.R., Duperron, S., and Weightman, A.J. (2010) Chemosynthetic bacteria found in bivalve species from mud volcanoes of the Gulf of Cadiz. FEMS Microbiol Ecol 73: 486-499.

Rosenberg, E., Koren, O., Reshef, L., Efrony, R., and ZilberRosenberg, I. (2007) The role of microorganisms in coral health, disease and evolution. Nat Rev Microbiol 5: 355362.

Rowley, A.F., Cross, M.E., Culloty, S.C., Lynch, S.A., Mackenzie, C.L., Morgan, E., et al. (2014) The potential impact of climate change on the infectious diseases of commercially important shellfish populations in the Irish Sea-a review. ICES J Mar Sci 71: 741-759.

Rubin, B.E., Sanders, J.G., Hampton-Marcell, J., Owens, S.M., Gilbert, J.A., and Moreau, C.S. (2014) DNA extraction protocols cause differences in 16S rRNA amplicon sequencing efficiency but not in community profile composition or structure. MicrobiologyOpen 3: 910-921.

Scheffer, M., Carpenter, S.R., Lenton, T.M., Bascompte, J., Brock, W., Dakos, V., et al. (2012) Anticipating critical transitions. Science 338: 344-348.

Schloss, P.D., Westcott, S.L., Ryabin, T., Hall, J.R., Hartmann, M., Hollister, E.B., et al. (2009) Introducing mothur: open-source, platform-independent, communitysupported software for describing and comparing microbial communities. Appl Environ Microbiol 75: 75377541.

Schmidt, T.S., Matias Rodrigues, J.F., and von Mering, C. (2014) Ecological consistency of SSU rRNA-based operational taxonomic units at a global scale. PLoS Comput Biol 10: e1003594.

Sergeant, M.J., Constantinidou, C., Cogan, T., Penn, C.W., and Pallen, M.J. (2012) High-throughput sequencing of 16S rRNA gene amplicons: effects of extraction procedure, primer length and annealing temperature. PLOS ONE 7: e38094.

Shade, A., Peter, H., Allison, S.D., Baho, D.L., Berga, M., Burgmann, H., et al. (2012) Fundamentals of microbial community resistance and resilience. Front Microbiol 3: 417.

Shea, K., and Chesson, P. (2002) Community ecology theory as a framework for biological invasions. Trends Ecol Evol 17: 170-176.

Sison-Mangus, M.P., Mushegian, A.A., and Ebert, D. (2015) Water fleas require microbiota for survival, growth and reproduction. ISME J 9: 59-67.

Sow, M., Durrieu, G., Briollais, L., Ciret, P., and Massabuau, J.C. (2011) Water quality assessment by means of HFNI valvometry and high-frequency data modeling. Environ Monit Assess 182: 155-170.

Stenuit, B., and Agathos, S.N. (2015) Deciphering microbial community robustness through synthetic ecology and molecular systems synecology. Curr Opin Biotechnol 33: 305-317.

Thebault, E., and Fontaine, C. (2010) Stability of ecological communities and the architecture of mutualistic and trophic networks. Science 329: 853-856.

Thomsen, P.F., Kielgast, J., Iversen, L.L., Moller, P.R., Rasmussen, M., and Willerslev, E. (2012) Detection of a diverse marine fish fauna using environmental DNA from seawater samples. PLoS ONE 7: e41732.

Trabal, N., Mazon-Suastegui, J.M., Vazquez-Juarez, R., Asencio-Valle, F., Morales-Bojorquez, E., and Romero, J. 
(2012) Molecular analysis of bacterial microbiota associated with oysters (Crassostrea gigas and Crassostrea corteziensis) in different growth phases at two cultivation sites. Microb Ecol 64: 555-569.

Trabal Fernandez, N., Mazon-Suastegui, J.M., VazquezJuarez, R., Ascencio-Valle, F., and Romero, J. (2014) Changes in the composition and diversity of the bacterial microbiota associated with oysters (Crassostrea corteziensis, Crassostrea gigas and Crassostrea sikamea) during commercial production. FEMS Microbiol Ecol 88: 69-83.

Wagner, E., Dumbauld, B.R., Hacker, S.D., Trimble, A.C., Wisehart, L.M., and Ruesink, J.L. (2012) Densitydependent effects of an introduced oyster, Crassostrea gigas, on a native intertidal seagrass, Zostera marina. Mar Ecol Prog Ser 468: 149-160.

Wang, Q., Garrity, G.M., Tiedje, J.M., and Cole, J.R. (2007) Naive Bayesian classifier for rapid assignment of rRNA sequences into the new bacterial taxonomy. Appl Environ Microbiol 73: 5261-5267.

Wang, Y., Naumann, U., Wright, S.T., and Warton, D.I. (2012) mvabund - an $\mathrm{R}$ package for model-based analysis of multivariate abundance data. Methods Ecol Evol 3: 471474.

Warton, D.I., Wright, S.T., and Wang, Y. (2012) Distancebased multivariate analyses confound location and dispersion effects. Methods Ecol Evol 3: 89-101.

Wegner, K.M., Volkenborn, N., Peter, H., and Eiler, A. (2013) Disturbance induced decoupling between host genetics and composition of the associated microbiome. BMC Microbiol 13: 252.

Wendling, C.C., and Wegner, K.M. (2013) Relative contribution of reproductive investment, thermal stress and Vibrio infection to summer mortality phenomena in Pacific oysters. Aquaculture 412: 88-96.

Wendling, C.C., and Wegner, K.M. (2015) Adaptation to enemy shifts: rapid resistance evolution to local Vibrio spp. in invasive Pacific oysters. Proc Biol Sci 282: 20142244.

Wendling, C.C., Batista, F.M., and Wegner, K.M. (2014) Persistence, seasonal dynamics and pathogenic potential of Vibrio communities from Pacific oyster hemolymph. PLoS ONE 9: e94256.

West, S.A., and Buckling, A. (2003) Cooperation, virulence and siderophore production in bacterial parasites. Proc Biol Sci 270: 37-44.

Widder, S., Besemer, K., Singer, G.A., Ceola, S., Bertuzzo, E., Quince, C., et al. (2014) Fluvial network organization imprints on microbial co-occurrence networks. Proc Natl Acad Sci USA 111: 12799-12804.

Wilcox, R.R., and Schönbrodt, F.D. (2014) The WRS package for robust statistics in $R$ (version 0.24). URL https://github.com/nicebread/WRS.

Williams, R.J., Howe, A., and Hofmockel, K.S. (2014) Demonstrating microbial co-occurrence pattern analyses within and between ecosystems. Front Microbiol 5: 358.
Wittebolle, L., Marzorati, M., Clement, L., Balloi, A., Daffonchio, D., Heylen, K., et al. (2009) Initial community evenness favours functionality under selective stress. Nature 458: 623-626.

Yachi, S., and Loreau, M. (1999) Biodiversity and ecosystem productivity in a fluctuating environment: the insurance hypothesis. Proc Natl Acad Sci USA 96: 14631468.

Zurel, D., Benayahu, Y., Or, A., Kovacs, A., and Gophna, U. (2011) Composition and dynamics of the gill microbiota of an invasive Indo-Pacific oyster in the eastern Mediterranean Sea. Environ Microbiol 13: 1467-1476.

\section{Supporting information}

Additional Supporting Information may be found in the online version of this article at the publisher's web-site:

Fig. S1. Correlation between the number of cultivable Vibrionaceae and Vibrionaceae evenness (A, B) or Vibrionaceae species richness $(C, D)$ in the haemolymph and solid tissues. The lines show a linear model fit and are used only as an illustration for the relationship. All conclusions are based on non-parametric Spearman's $\rho$ coefficient. $\rho=$ Spearman's $\rho$.

Fig. S2. Association networks of haemolymph OTUs grouped by oyster origin and treatment showing only positive correlations (colour, shape and size legend as in Fig. 6). Separate subnetworks thus represent negatively correlated modules of the complete network. Arrows point to the 'seawater' cluster, while the ellipses encircle all parts of the network where the other OTUs/motifs shared by the oyster groups are found.

Table S1. Pearson residuals for the $\chi^{2}$ test of end-point survival between the four oyster groups. Texel non-antibiotic treated oysters are the only group with the higher than expected mortality.

Table S2. Multivariate generalized linear model (negative binomial) showing significant differences at the class level between the oyster tissues, origin and treatment.

Table S3. Multivariate generalized linear model (negative binomial) showing effects of oyster origin and treatment on the abundance of genera within the haemolymph. Only genera with significant differences are listed.

Table S4. Multivariate generalized linear model (negative binomial) showing effects of oyster origin and treatment on the OTU abundance within the haemolymph. Only OTUs with significant differences are listed.

Table S5. Properties of original haemolymph networks and average of 1000 random networks with same number of nodes and edges.

Table S6. Multivariate generalized linear model (negative binomial) showing effects of oyster origin and treatment on the genera abundance in solid tissues. Only genera with significant differences are listed. 